\title{
Foundation architecture of telemedicine system services based on Health 4.0 concept
}

\author{
Alisa Dubgorn ${ }^{1}$, Olga Kalinina ${ }^{1}$, Anastasia Lyovina ${ }^{1 *}$, and Oksana Rotar $^{2}$ \\ ${ }^{1}$ Peter the Great St.Petersburg Polytechnic University, Institute of Industrial Management, Economics \\ and Trade, Higher School of Business Management, 195251, Polytechnicheskaya st., 29, Russian \\ Federation \\ ${ }^{2}$ Federal State Budgetary Establishment "National Medical Research Center of V.A. Almazov" of the \\ Ministry of Health of the Russian Federation, 197341, Akkuratova st., 2, Russian Federation.
}

\begin{abstract}
Telemedicine as an application area of the modern medicine is flourishing supported by the corresponding technologies development. Development of telemedicine technologies is one of the main trends in digitalization of health care service put into practice within the Health 4.0 concept. Implementation of telemedicine systems is particularly topical for countries possessing a great territory, due to which the problem occurs to provide equal access to specialized and hi-tech medical aid for all inhabitants in the country. Creation of the effective telemedicine system for rendering medical aid to patients in remote locations requires a system approach to engineering and implementation of such system. Represented in the article is a structure of the telemedicine system engineering and implementation project with the use of service-oriented approach to simulation of socialeconomic systems, as well as requirements to upper level services of such system within the first stage of the project.
\end{abstract}

\section{Introduction}

One of the factors characterizing health care services in a country is its availability, including hi-tech and specialized medical aid. The character of territorial distribution of centers, providing hi-tech and special medical aid, on the one hand, puts forward a problem to ensure availability of such medical aid for patients from remote locations, on the other hand - a problem of effective use of resources by centers rendering such aid. It is impossible to solve these problems without application of modern telemedicine technologies - computer and telecommunication technologies for acquisition and exchange of medical information.

Routing of patients in the process of detection, monitoring and rendering hi-tech and specialized medical service is not a linear motion from one point to the other. Since there is a tendency towards personalized medicine it is necessary to provide a possibility to process, store, and analyze large volumes of patient personal data. Since there is a complicated combination of factors (not only medical ones) determining the patient readiness for certain treatment it is necessary to make definite decisions (medical and administrative) after each

*Corresponding author: alyovina@gmail.com 
process stage, which shall influence the further patient pathway. The hi-tech and specialized system of medical services features as follows [1]:

- Complexity and dynamics of processes;

- Uncertainty in demand and availability of resources;

- Patient-oriented approach;

- High speed and flexibility of decision making;

- Necessity in balancing the medical and economical efficiency.

Similar to many spheres of activity the modern health care becomes more and more technological; the advanced medical knowledge turns out to be concentrated in the special medical centers. The consequence of such centralization is the increase in a distance between such centers and potential patients who need the medical aid. As a result, many patients have no opportunity to get the precise diagnosis and the corresponding treatment. This problem is particularly acute for countries possessing the significant territory (for example, Russia, India, China, Brazil). The patient monitoring and routing process at rendering the specialized medical service to patients from remote locations requires a number of factors to be accounted (not only medical ones), which determine the patient readiness for certain treatment. Besides, after each process stage it is necessary to make definite decisions (medical and administrative) which influence the further patient pathway. Representation of specialized medical service to patients in remote locations is a very information-intensive process, since it requires proper acquisition, transmission, processing and analysis of large amount of data on patients and effective system of decision making on its base. Since the development of capital-intensive technological health care is to be continued, the actual task is development of technological and organizational principles of telemedicine system creation which shall provide data acquisition, storage, transmission, processing and analysis, as well as medical and administrative decision support in the process of rendering specialized medical aid to the territorially remote patients.

Due to development of technologies, including information-communication ones, at the present time the tendencies to digitalization are observed in many spheres of economical activity. The most known digitalization concept is the Industry 4.0 [2]. This concept means transition to completely automated digital production controlled by the intellectual systems in real-time mode with constant interaction with external environment, going beyond one enterprise, with a prospective of integration into the global industrial network of Things and Services[3]. The Health 4.0 concept being an "industry-specific interpretation" of the Industry 4.0 concept in medicine is aimed at increase of efficiency, decrease in expenditures and transition to customized services for patients. By using such technologies as Big Data, IoT, M2M, cloud computing the medical organization can increase availability and economical efficiency of medical aid, thus improving the patients' life quality [4]. Development of telemedicine systems is impossible without application of modern technologies in the sphere of data acquisition, processing, transmission, storage and analysis, as well as other modern technologies.

Allotted in the article is a task of setting requirements to the telemedicine system services developed according to the Health 4.0 concept and making it possible to provide an access to specialized and hi-tech medical assistance for remotely located patients. 


\section{Methodology}

The Health 4.0 is a strategic concept for the health care field based on the Industry 4.0 concept. The purpose of the Health 4.0 is to ensure digital transformation of the field in order to make the health care system more customized and to provide patients health care in realtime mode thanks to the wide use of CPS (cyber-physical systems), cloud computing, Internet of Everything, including things, services and people, as well as mobile networks under development $(5 \mathrm{G})$. With the help of cyber-physical systems, visualized software blocks and modern data processing technologies the patients can be "virtualized" to make it possible to receive and analyze data on patients' health in any place in real-time mode. This will create prerequisites for development of personalized and precision medicine.

At the present time, the leading medical organizations in the country which attract a large number of scientific \& research organizations and commercial enterprises develop approaches, methods and the corresponding material-and-technical infrastructure to detect and monitor the patients of pathological condition. In order to solve this task the use is made of such technologies as telemedicine, Internet of Things (IoT), mobile and electronic health care (mHealth and eHealth), cloud computing, Big Data, predictive analytical systems[5]. At the present time there is a great number of the described examples for modern technologies application in medicine (e.g., [6-10]). So, significant results are achieved in the sphere of development and practical implementation of the detection and monitoring system for patients with heart conditions, using:

- mobile applications for acquisition and transmission of patients condition parameters;

- telemedicine technologies for remote communication between patients and doctors;

- processing and analysis technologies of Big Data received from patients;

- predictive analytical systems for forecasting of patient condition dynamics.

Many works are dedicated to the issues concerning improvement of individual medical aid types rendering with the use of telemedicine technologies [10-12]. However, not many works could be found concerning the issues of a complex telemedicine system architecture development. Considered in [13] are approaches to increase availability and improve quality of medical assistance for the hard-to-reach and remote inhabited localities of the Russian Federation, implemented with the use of mobile telemedicine complexes (MTC) within the project on creation of telemedicine systems (TMS). The authors have analyzed the possible TMS architectures, have revealed deficiencies of the two-segment TMS the main of which is the system disintegration from a network of the ambulatory prevention and treatment facilities (PTF) existing in the RF regions, have proposed the use of three-segment TMS architecture which includes the existing ambulatory treatment facilities into the scheme of informational interaction besides mobile telemedicine complexes and TMS in-patient clinics. Absence of full-fledged legal environment for rendering medical assistance in such a format is also mentioned in publications dedicated to organization of telemedicine systems [14]. The analysis of international experience of developments in the sphere of telemedicine solutions has shown that there is a demand in investigation aimed at development of a complex solution on rendering medical assistance in the remote locations with the use of telemedicine concept, including the elaborated managerial, information-and-technological and hardware components.

At creation of the efficient telemedicine system it is necessary to use a complex approach which makes it possible to consider all various components in their interrelation and interdependence. In the present management such approach is an enterprise architecture which allows creating the efficient control systems consisting of the business-process systems, organizational structure, information systems, applications, technological 
infrastructure [15]. Described in $[16,17]$ is the elaborated service-oriented approach to analysis and re-engineering of the enterprise architecture and its elements. Such approach allows efficient formation and re-formation of the management system of enterprises and other social-economical systems by considering interrelation and interdependence of various elements of the control system. Application of such approach in the project of development and implementation of the data acquisition, transmission, processing and analysis system for patients in the remote locations shall make it possible to develop an effective complex solution taking into account a great number of various components of rendering the remote medical assistance. Such approach in development and re-engineering of the system architecture assumes the initial determination of requirements to the system services on the basis of which the whole system will be established.

Structure of the project on development and implementation of the telemedicine system was created in the article, and requirements to services of such system within the first stage of the developed structure of the project were established.

\section{$3 \quad$ Results}

In the present work the requirements to services of the telemedicine system created within the Health 4.0 concept are established. The developed telemedicine system must have the following characteristics:

- Reach the most remote and / or limited resource;

- Develop the qualified resource pool in the territorially remote points;

- Provide quick access of patients to experts and resources;

- Help in rendering proper patient care in conditions of constant monitoring, emergency assistance and personal injury, as well as in rehabilitation;

- Be self-supporting thanks to synergetic interaction between the concerned parties in the system of medical aid rendering;

- Include elements of computer-assisted training providing a system of medical decision making support.

Implementation of telemedicine system for rendering assistance to patients in remote locations is intended to provide the following advantages:

- Increase in patient satisfaction. In individual cases there is no longer any necessity in personal meetings with doctors from the territorially remote regions, the time of patient waiting in queue and the time required for document management can be decreased, the risk of errors and delays connected with writing disposals, prescriptions, registration of patients can be reduced. Besides, the main attention will be drawn to expansion of rights and possibilities of patients through patient training, extension of interaction with patients and implementation of educational and prevention programs.

- Increase in quality of medical assistance. The higher level of patient servicing is provided, among other things, by means of complete and accurate electronic arrangement of patients which shall reduce a number of errors, omissions or duplication of information and actions based thereon.

- Increase in work performance of medical stuff. Doctors and other medical stuff will devote more time to patients thanks to significant automation, in particular concerning the document management process. This will make it possible for medical stuff to devote more time to patients, to service more patients or to devote the saved time to other productive types of activity.

- Increase in operational efficiency of medical establishments engaged in the system of medical aid rendering to patients from the remote locations. Health care 
organization can eliminate duplication of functions and administrative delays by means of automation and effective data exchange. The risk of errors decreases due to reduction in the volume of manual information input.

The main stages of the telemedicine system implementation project are given below:

1. Creation of requirements to telemedicine system services on detection and monitoring of pathological condition patients in the remote locations;

2. Creation of management architecture for telemedicine system on detection and monitoring of pathological condition patients in the remote locations;

3. Creation of a model for processes of detection and monitoring of pathological condition patients with the use of telemedicine technologies;

4. Establishment of requirements to:

a. data processing and analysis model for telemedicine system;

b. business-analysis system;

c. hardware components (technological infrastructure) of the telemedicine system developed, including analysis of requirements for deployment of communication infrastructure;

d. mobile applications and personalized data acquisition and transmission system for patient management implemented with the use of "Internet of Things" technology;

5. Development of:

a. data models for detection and monitoring of pathological condition patients with the use of telemedicine technologies;

b. data processing and analysis, including a platform for data storage and exchange, business-analysis system;

c. technological infrastructure of telemedicine system;

6. Development of:

a. a platform for data storage and exchange;

b. mathematical, simulation and statistical models for decision making support within the detection and monitoring system of pathological condition patients with the use of telemedicine technologies;

c. methodology of computer-based education for the data exchange and storage platform;

d. BI-systems;

e. mobile applications for acquisition and transmission of personalized patient monitoring data;

7. Complete set, construction and installation works, startup and adjustment works to create the technological infrastructure;

8. Integration of:

a. developed business-analysis system and data exchange and storage platform;

b. developed mobile application and data exchange and storage platform;

c. patient management personalized data acquisition and transmission devices implemented with the use of "Internet of things" technology, mobile application and data exchange and storage platform

9. Creation of the test database for pilot tests of the data processing and analysis model being developed;

10. Pilot tests of individual components and the whole telemedicine system, 
The first stage of the telemedicine system development project - creation of requirements to the system services - is considered in the present article. Proposed in [18] is classification of Smart Hospital services with subdivision into longtermness of their implementation perspectives. Similar to the proposed classification the following list of the necessary telemedicine system services has been developed (Table 1). It should be explained that this list relates just to telemedicine system and stipulates availability of general services of medical aid rendering system (according to [18]).

Table 1. Upper level services of telemedicine system.

\begin{tabular}{|l|l|l|}
\hline \multicolumn{1}{|c|}{$\begin{array}{c}\text { Upper level } \\
\text { services }\end{array}$} & \multicolumn{1}{|c|}{ Service description } & \multicolumn{1}{c|}{$\begin{array}{c}\text { Technologies used at } \\
\text { service implementation }\end{array}$} \\
\hline $\begin{array}{l}\text { Mobile } \\
\text { telemedicine } \\
\text { complex }\end{array}$ & $\begin{array}{l}\text { Represents the hardware at the location } \\
\text { of medicine services rendering, is } \\
\text { intended for acquisition of initial data } \\
\text { from patients, including application of } \\
\text { diagnostic equipment. }\end{array}$ & $\begin{array}{l}\text { IoT } \\
\text { Technologies of data } \\
\text { transmission } \\
\text { Cyber-physical systems } \\
\text { (CPS) }\end{array}$ \\
M2M connectivity
\end{tabular}




\begin{tabular}{|c|c|c|}
\hline $\begin{array}{l}\text { Upper level } \\
\text { services }\end{array}$ & Service description & $\begin{array}{l}\text { Technologies used at } \\
\text { service implementation }\end{array}$ \\
\hline $\begin{array}{l}\text { Possibility of } \\
\text { patient } \\
\text { participation }\end{array}$ & $\begin{array}{l}\text { Involvement of patients in the process } \\
\text { of their own health support to achieve } \\
\text { the best result. This service involves a } \\
\text { wide spectrum of possibilities - from } \\
\text { patient portals to strategies in social } \\
\text { networks, from tracking the vital } \\
\text { functions with the help of portable } \\
\text { devices for patients actively } \\
\text { participating in the health-improving } \\
\text { programs }\end{array}$ & $\begin{array}{l}\text { mHealth } \\
\text { Social Media Marketing } \\
\text { (SMM) } \\
\text { Internet of Things (IoT) }\end{array}$ \\
\hline Data management & $\begin{array}{l}\text { Development and implementation of } \\
\text { architectures, policies, practices and } \\
\text { procedures for effective control over the } \\
\text { enterprise information lifecycle }\end{array}$ & $\begin{array}{l}\text { Business-analyses } \\
\text { Big Data } \\
\text { Cloud technologies }\end{array}$ \\
\hline Data storage & $\begin{array}{l}\text { Data storage is created on the basis of } \\
\text { different sources, provides storage of } \\
\text { the current and historical data used for } \\
\text { creation of analytical reports }\end{array}$ & $\begin{array}{l}\text { Business-analyses } \\
\text { Big Data } \\
\text { Cloud technologies }\end{array}$ \\
\hline $\begin{array}{l}\text { Decision making } \\
\text { support system }\end{array}$ & $\begin{array}{l}\text { Allows for substantiation of decision } \\
\text { making by processing the various } \\
\text { accumulated data }\end{array}$ & $\begin{array}{l}\text { Business-analyses } \\
\text { Big Data } \\
\text { Computer-based education } \\
\text { Mathematical, simulation } \\
\text { modeling, statistical } \\
\text { analysis } \\
\end{array}$ \\
\hline $\begin{array}{l}\text { Determination of } \\
\text { position in real- } \\
\text { time mode }\end{array}$ & $\begin{array}{l}\text { The position determination system in } \\
\text { real-time mode automatically identifies } \\
\text { and tracks position of objects or people } \\
\text { in real time with the use of tags and } \\
\text { sensors }\end{array}$ & $\begin{array}{l}\text { IoT } \\
\text { Geoinformation systems } \\
\text { (GIS) }\end{array}$ \\
\hline $\begin{array}{l}\text { Monitoring of } \\
\text { patients' state }\end{array}$ & $\begin{array}{l}\text { Wide spectrum of services rendered at a } \\
\text { distance to patients with detected } \\
\text { chronic illnesses or having passed } \\
\text { certain treatment. Includes the condition } \\
\text { control and public awareness campaign } \\
\text { carried out by specialists for patients' } \\
\text { care management }\end{array}$ & $\begin{array}{l}\text { eLearning } \\
\text { IoT } \\
\text { Cyber-physical systems } \\
\text { (CPS) } \\
\text { M2M connectivity }\end{array}$ \\
\hline
\end{tabular}

In order to implement the listed telemedicine system services it is supposed to use the following methods, approaches and technologies:

- telemedicine technologies. The character of the territorial distribution of centers rendering hi-tech and specialized medical assistance in Russia, as well as peculiarities of patient routing processes in the course of such assistance rendering stipulate the necessity in implementation of modern telemedicine technologies which make it possible to remotely exercise individual constituents of the medical assistance rendering process. At that, efficient resource use of centers rendering such assistance is provided;

- Big Data management technologies. Medical assistance rendering in the territorially distributed locations is connected with a necessity in personalized acquisition, processing and analysis of data on patients within the region and even the country. 
Management of such big volumes of information is possible thanks to the use of modern technologies of big data management;

- Internet of Things technology. Management and control of patients' condition before and after rendering the hi-tech and specialized medical assistance must be of personalized and continuous character. Technical implementation of such monitoring of patients condition is possible by the use of "Internet of Things" technology that means acquisition of information from the object (patient) with the use of special devices and transmission of information through Internet for subsequent processing (including the use of Big Data management technologies);

- M2M connectivity. The technology is directly connected with "Internet of Things", provides data exchange between machines (including cyber-physical systems) without human participation;

- predictive analytical systems. Acquisition and analysis of data on patient condition for forecasting thereof, performed with the use of predictive analytical systems, make it possible to increase efficiency of the made medical and managerial decisions in the system of rendering hi-tech and specialized medical assistance;

- computer-based education. The use of computer-based education at operation with big volumes of patient data is aimed at support of making managerial decisions in medicine concerning development of individual paths of patients routing, evaluation of risks and classification of patients, as well as diagnostics in real-time mode;

- mobile networks 5G. Provides a possibility of multi-frequency connection and multi-modality, including NB-IoT and mobile service in order to provide information exchange between physical and virtual worlds [4];

- cyber-physical systems (CPS). Represent integration of computer-based and physical processes where embedded computers and networks perform monitoring and control of physical processes with feedback cycles, as a rule. The specific applications for health care can be connection of Body Area Networks systems and sensors to disease control platforms with the use of feedback auto-regulation cycles or feedback with the help of devices (e.g., smart phones) [4];

- mathematical modeling, simulation modeling and statistical analysis. Operation with big data requires elaboration of models on their processing and analysis. Mathematical, simulation and statistical models of data processing are planned to be implemented in the developed business-analysis system.

\section{Conclusions}

Telemedicine as an applied sphere of the modern medicine is flourishing now which is conditioned both by internal and external reasons. On the one hand, the tendency towards value-based medicine is observed in the health care field that means a growth of patient role at creation of requirements to the quality of medical services. On the other hand, the rapid development of technologies makes implementation of new services in the health care field principally possible. Thus, favorable conditions for development of value-based medicine are created, in particular to provide equal access to the services of specialized and hi-tech medical assistance for all patients in the country.

The telemedicine system providing detection, control, medical assistance and condition monitoring of patients in remote locations represents a complex of different control objects. Creation of such system requires complex approach to its engineering and implementation. Represented in the article is a structure of the project on engineering and implementation of telemedicine system with the use of service-oriented approach to modeling of socialeconomic systems from establishment of requirements to pilot tests. Service-oriented 
engineering of telemedicine system is aimed at creation of the efficient, flexible and evolutionary system by taking into account the interrelation and interdependence of system components at its creation. Formulated in the article are requirements to upper level services of such system which represents the first stage of the telemedicine system development and implementation project. Besides, a potential of the modern digital technologies at implementation of the required services is determined. Implementation of the proposed architecture of services is intended to ensure high medical and economic efficiency of rendering specialized and hi-tech assistance to patients in the remote locations by far-sighted use of resources of both medical organizations in situ and specialized medical centers of federal importance.

The topic of the present article can be developed by elaboration of the telemedicine system IT-architecture according to the established requirements to services, as well as investigation of implementation methods for individual telemedicine system services, including the use of key technologies of the Health 4.0 concept.

\section{References}

1. E. A. Ryngach, T. V. Treshkur, A. A. Tatarinova, E.V. Shlyakhto, Terapevticheskii Arkhiv (2017)

2. M. Herman, T. Pentek, B. Otto. Design principles for Industrie 4.0 scenarios. Technical University of Dortmund, Faculty of Engineering, Audi Endowment Chair Supply Net Order Management [online], Available at: http://www.leorobotics.nl/sites/leorobotics.nl/files/bestanden/2015\%20-\% 20Hermann $\% 20$ Pentek $\% 20 \% 26 \% 20$ Otto $\% 20$ - $\% 20$ Design $\% 20$ Principles $\% 20$ for $\%$ 20Industrie $\% 204 \% 20$ Scenarios.pdf (2017)

3. The Fourth Industrial Revolution. Popular about the main technological trend of the XXI century. Available at: http://www.tadviser.ru/index.php/Article:Forth_industrial_revolution_(Industry_4.0). (2017)

4. C. Thuemmler, C. Bai, (eds.) Health 4.0: How Virtualization and Big Data are Revolutionizing Healthcare, DOI 10.1007/978-3-319-47617-9_2 (2017)

5. I. V. Ilin, O. Yu. Iliashenko, A. I. Levina. Proceedings of the 29 th IBIMA Conference Sustainable Economic Growth, Education Excellence, and Innovation Management through Vision 2020 (2017)

6. J.M.L.P. Caldeira, J.J.P.C. Rodrigues, P. Lorenz, IEEE Communications Magazine 50 (5) (2012)

7. J.J.P.C. Rodrigues, I. De La Torre, G. Fernández, M. López-Coronado, Journal of medical Internet research 15(8) (2013)

8. V. Arun, S.K. Padma, V. Shyam, Med Med Sci Res 4(189) (2015)

9. J. Santos, J.J.P.C. Rodrigues, B.M.C. Silva, J. Casal, K. Saleem, V. Denisov, Journal of Network and Computer Applications 71 (2016)

10. V. Arun, V. Shyam, S.K. Padma, Primary Health Care 5 (210) (2015)

11. V. N. Rostovtsev, T. I. Terekhovich Organizational-technological system of telemedicine clinical examination [online] Available at: http://minzdrav.gov.by/dadvfiles/001079 754732 2_ 5 rostovc.pdf (2017)

12. T. S. Smal, V. D. Zavadovskaya, I. A. Deyev. Use of telemedicine technology for expert evaluation of X-ray examination quality for osteo-articular system in conditions of remote regions [online] Available at: http://www.rejr.ru/volume/26/11.pdf (2017) 
13. G. Ya. Ilyushin, V. I. Limansky. Rendering medical assistance to population with the use of mobile telemedicine systems [online] Available at: http://www.mathnet.ru/links/5c7df673fd59c0a7d674df4be31b7b0c/ssi507.pdf (2017).

14. A. O. Lositsky, E. L. Borshchuk, A. D. Chuprov. Legal issues of telemedicine treatmentdiagnostic services implementation into the state finance system at the present time [online] Available at: http://www.eyepress.ru/article.aspx?24747. (2017)

15. M. Lankhorst, et al. Enterprise Architecture at Work. Modelling, Communication and Analysis (2017)

16. I. V. Ilin, O. Yu. Iliashenko, A. I. Levina, Proceedings of the $28^{\text {th }}$ IBIMA ConferenceVision 2020: Innovation Management, Development Sustainability, and Competitive Economic Growth. (2016)

17. I. V. Ilin, K. V. Frolov, A. A Lepekhin, Proceedings of the 29th IBIMA - Sustainable Economic Growth, Education Excellence, and Innovation Management through Vision 2020 (2017)

18. Smart hospital services catalogue. Available at: http://awtg.co.uk/white-paper/smarthospitals-service-catalogue/ (2017) 